\title{
Sociedad Chilena de Pediatría: Desafíos hacia el Bicentenario
}

\author{
OSCAR HERRERA G. ${ }^{1}$ \\ 1. Presidente Sociedad Chilena de Pediatría.
}

La Sociedad Chilena de Pediatría, es actualmente la sociedad científica más numerosa en el país, con casi 2000 socios distribuidos a lo largo y ancho de todo el país. En ella participan activamente profesionales médicos y otros ligados a la salud y bienestar del niño, que participan en las distintas Filiales, Ramas y Comités; como representantes ante organismos científicos nacionales e internacionales como ALAPE, CONACEM, ASOCIMED, ASOFAMECH y APICE; como editores de Revista Chilena de Pediatría, Magazine Estetoscopio y página web; y otros.

Los desafíos que nuestra Sociedad Chilena de Pediatría nos demanda hoy día son múltiples y requieren de una gran entrega y trabajo de todos, especialmente de su Directorio.

Quisiera destacar algunos de los objetivos que se ha planteado el Directorio de SOCHIPE para el período 2009-2010:

Tal como señalan nuestros Estatutos, nuestra principal preocupación es el perfeccionamiento y desarrollo de los pediatras, el estudio de los problemas relacionados a la salud, educación, derechos y bienestar del niño y adolescentes, así como la superación técnica y científica de sus miembros.

Para que estos objetivos se puedan cumplir a lo largo de todo el país y con el propósito de que las Filiales de Arica a Punta Arenas tengan representatividad en el Directorio central, se ha aprobado la incorporación de un representante de la zona norte y uno de la zona sur, inicialmente con derecho a voz y una vez aprobados los cambios necesarios en los Estatutos tendrán derecho a voto. Los presidentes de Filiales designados viajarán cada 15 días a reunión de Directorio trayendo los aportes de sus respectivas zonas geográficas.

Otro de los primeros acuerdos de trascendencia tomados por este Directorio, ha sido el aprobar la creación de nuevas Ramas que vienen a completar la extensa lista de subespecialidades pediátricas. Desde hace un par de años hemos invitado a nuestro Congreso de Pediatría a odontopediatras, cirujanos pediatras, oftalmólogos pediatras quienes también participan en la atención integral de niños y adolescentes. También formaremos las Ramas de Dermatología, Radiología y el Comité de Medicina Deportiva, de tanta importancia hoy en día, con el aumento de la obesidad, sedentarismo y enfermedades crónicas. ¡Cuanto podemos hacer los pediatras en términos de prevención, guiados por especialistas en el campo del deporte y vida saludable!.

Mención especial merece la creación de la Rama de Atención Primaria que reúne a los médicos que atienden pediatría en los innumerables consultorios del país, la gran mayoría de ellos sin haber efectuado una formación formal en pediatría. Su directiva ha aceptado con gran satisfacción unirse a nuestra sociedad y ha manifestado que es una situación histórica para ellos que una sociedad científica los acoja y los incorpore a sus diferentes actividades académicas. Creemos es un deber elevar el nivel científico y técnico de estos profesionales y esperamos la colaboración de nuestras Ramas y Comités para 
organizar cursos de educación continua en diferentes tópicos pediátricos, cuyo único norte será el perfeccionamiento de estos profesionales, en beneficio final de nuestros niños.

Otro de los objetivos que se ha propuesto este Directorio, es la reactivación de la Fundación Sociedad Chilena de Pediatría que permitirá atraer recursos para actividades científicas específicas obtenidos de empresas farmacéuticas y de otros rubros. La Fundación tiene personería jurídica desde el año 2001 y fue creada bajo la presidencia de la Dra. Nereyda Concha, permaneciendo inactiva por variadas circunstancias durante estos años.

Recientemente y en coincidencia con la celebración del Día Internacional de la Mujer, la Sociedad Chilena de Pediatría junto con el Colegio Médico de Chile, hizo un llamado a la Presidenta de la República para que envíe al Congreso el Proyecto de ley "Prolongación de la licencia de post natal a 6 meses para asegurar el apego y la lactancia materna", lo que permitiría transparentar el tema de las licencias fraudulentas por enfermedad grave en hijo menor de 1 año que hoy las madres solicitan para permanecer un tiempo más prolongado junto a sus hijos. Sabemos que al Ejecutivo le preocupa que se perpetue el vicio de estas licencias entre los 6 y los 12 meses, por lo que la Sociedad de Pediatría ha ofrecido buscar en conjunto un mecanismo de control a través de nuestros especialistas como garantes de un estricta visación de patologías que ameriten efectivamente extender la licencia más allá de los 6 meses. Las respectivas Ramas de subespecialidades han enviado las listas de patologías crónicas que requieren el cuidado materno durante el primer año de vida.

A fines del año recién pasado se promulgó el Decreto $N^{0} 57$ que se refiere al Reglamento de Certificación de las Especialidades y Subespecialidades lo que atañe directamente a la formación y certificación de especialistas médicos en nuestro medio. Si bien muchas sociedades científicas coinciden en que los artículos permanentes de dicho reglamento son positivos, la mayoría ha manifestado su preocupación por los dos artículos transitorios que faculta a los Directores de los Servicios de Salud a reconocer como especialistas o subespecialistas a quienes se hayan desempeñado durante 5 años en establecimientos de los Servicios de Salud. Nuestra Sociedad está participando activamente en reuniones en ASOFAMECH (Asociación de Facultades de Medicina de Chile), en ASOCIMED (Asociación de Sociedades Científicas Médicas) y en APICE (Agencia Acreditadora de Programas y Centros Formadores de Especialistas Médicos) las que esperan contribuir a definir la mejor y más transparente forma de certificar a los pediatras y subespecialistas de nuestro país.

Finalmente, hemos continuado en la senda de posesionar a nuestra Sociedad en el medio nacional con la participación inmediata ante temas contingentes relacionados con los niños y adolescentes en los diferentes canales de prensa escrita y medios audiovisuales en general, para lo cual se contrató a fines de la presidencia de la Dra. Lidya Tellerías una empresa de relaciones públicas que se encuentra efectuando una labor de gran apoyo y relevancia para la Sociedad.

Quiero invitar a todos nuestros socios, profesionales de apoyo pediátrico, becados y estudiantes a participar activamente en la SOCHIPE, junto a su directorio 2009-2010, formado por su vicepresidente Dr. Francisco Moraga (Nutriólogo y Sub Jefe de Servicio de Pediatría, Hospital San Borja Arriarán); Secretario general Dr. Carlos Saieh (Nefrólogo, Clínica Las Condes); Tesorero Dr. Jorge Vergara (Infectólogo, Jefe de Servicio de Pediatría Hospital Exequiel González Cortés), Secretaria de Actas Dra. Pilar Monteverde (Pediatra Hospital Clínico Universidad de Chile); y los Directores Dra. Patricia Mena (Neonatóloga, Jefa de Servicio de Neonatología, Hospital Sótero del Río), Dra. Teresa Alarcón (Gastroenteróloga, Jefa de Unidad Hospital San Juan de Dios), Dr. Luis Felipe González (Nefrólogo, Hospital Roberto del Río) y Dr. Hernán Sepúlveda (Broncopulmonar, Sub Jefe Unidad de Lactantes Hospital Luis Calvo Mackenna).

Una invitación especial a asistir y participar en el XLIX Congreso Chileno de Pediatría a efectuarse en la hermosa ciudad de Valdivia, entre el 28 y 31 de Octubre. Junto con las actividades científicas y de extensión, es un momento de entretención, esparcimiento, encuentro con amigos y un alto en la sobrecargada agenda anual.

Nos vemos en la ciudad de los Ríos. 